\title{
Utility of Computed Tomography in Interval Appendectomy for Actinomycotic Appendicitis.
}

\author{
Ho Seung Kim¹, Jung Hoon Lee ${ }^{2}$ \\ Departments of ${ }^{1}$ Surgery and ${ }^{2}$ Pathology, The Armed Forces Capital Hospital, Gyeonggi-do, South Korea.
}

\section{Corresponding Author: \\ Dr. Ho Seung Kim \\ Email: thankhjk@naver.com}

This is an Open Access article distributed under the terms of the Creative Commons Attribution License (creativecommons.org/ licenses/by/3.0).

Received Accepted

Published
May 30, 2017

August 25, 2017

October 5, 2017

\begin{abstract}
Background: Appendicitis is common medical emergency requiring surgery although currently some surgeons choose non-operative management based on the patient's overall health status. After conservative management, surgeons usually obtain a computed tomography (CT) scan particularly when the patient's clinical manifestations are questionable. Actinomycosis could be a rare cause of an insidious clinical presentation of appendicitis. Case Report: We report a case of appendicitis caused by actinomycosis with follow up using CT scans during non-operative management before surgery.Conclusion: Surgeons should consider actinomycosis in the differential diagnoses during nonoperative management of appendicitis.
\end{abstract}

Keywords: Actinomycosis, Appendicitis, Computed Tomography, Humans, Radionuclide Imaging.

\section{Introduction}

Actinomycosis is an extremely rare disease [1]. Only a few studies have reported cases of abdominal actinomycosis detected in the appendix [2-7], and all but one patient among the previously reported cases underwent an urgent appendectomy, We initially treated the patient with non-operative management followed by interval appendectomy, although his CT scan showed findings of acute appendicitis, we determined that the patient was in the late course of the disease. Fortunately, using a CT scan before surgery, we could confirm the response to four weeks of antibiotic therapy. We report a case of actinomycosis in a patient with appendicitis whose course was followed with a CT scan, after four weeks of antibiotic therapy.

\section{Case Report}

A20-year-old man presented to the gastroenterology division of our hospital with a 5-day history of vague abdominal pain, which had been intermittent and long standing. Suspected to be suffering from inflammatory bowel disease, he underwent a colonoscopy two weeks later, and was noted to have acute inflammation (hyperemia, edema, erosions) around the appendiceal orifice, but no other abnormal findings including at the terminal ileum [Fig.1].

The patient was transferred to the emergency department for further evaluation to rule out appendicitis. He had no specific medical and family history. Physical examination revealed no obvious abdominal tenderness and rebound tenderness, and he had no other symptoms, such as fever, nausea, diarrhea, or hematochezia. Abdominal pain was seen to have improved from the time of his first visit to the hospital two weeks ago.

Laboratory tests showed leukocytosis $(13,830 / \mu \mathrm{L} ; 89.3 \%)$, an elevated C-reactive protein (CRP) level (1.22 $\mathrm{mg} / \mathrm{dL})$ and an elevated erythrocyte sedimentation rate (ESR) 
(19 mm/hour). Contrast-enhanced abdominal CT showed a $1.8 \mathrm{~cm}$ sized edematous wall thickening of the appendix with a tiny appendicolith and lymph node enlargement in the right lower quadrant [Fig.2A].

Based on the fact that the patient had been seen in the late course of appendicitis, nonoperative management with antibiotics was chosen as the treatment strategy. Following intravenous administration of ceftriaxone and metronidazole, he was treated with oral cefpodoxime for four weeks. He did not show any change in symptoms during non-operative management and his laboratory tests were seen to normalize. A followup CT to determine the need for an appendectomy after four weeks of antibiotic therapy did not show any significant interval change [Fig.2B].

The patient underwent laparoscopic interval appendectomy after four weeks of nonoperative management. Operative findings showed an inflamed pelvic appendix with multiple adhesions between it and adjacent organs. On gross examination, the serosal surface of the appendix, measuring $5.5 \mathrm{~cm}$ in length and $0.8 \mathrm{~cm}$ in diameter, was covered with fibrinous exudates, and an impacted appendicolith in its lumen. Histologically the specimen revealed granulomatous appendicitis [Fig.3A]. A typical sulfur granule, surrounded by heavy neutrophilic infiltration, was observed in the mucosa [Fig.3B]. Filamentous organisms were identified in the sulfur granule using Grocott's methenamine silver stain [Fig.3C], confirming a diagnosis of actinomycotic appendicitis. The patient had an uneventful recovery and received long-term antibiotic therapy with penicillin.

\section{Discussion}

Actinomycosis is a rare and clinically slowly progressive disease $[1,8]$. With an incidence rate between 1/300,000 and 1/1,000,000 [9], abdominal actinomycosis (AA) constitutes $20 \%$ of all cases of actinomycosis [2]. The appendix and ileo-

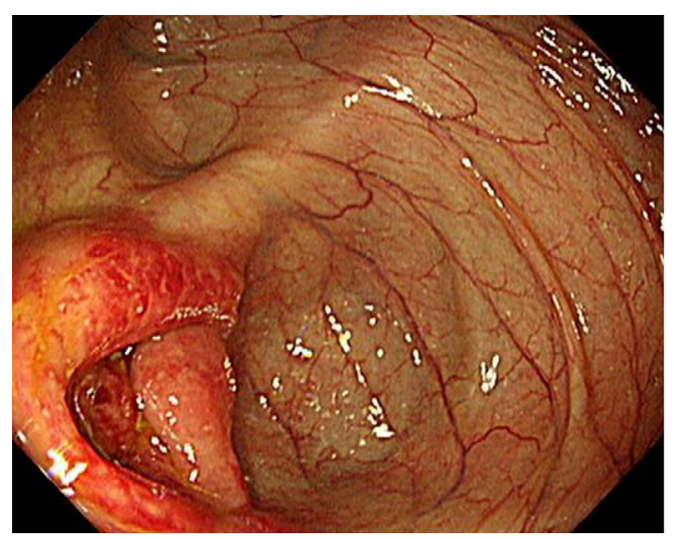

Fig.1: Colonoscopy showing acute inflammation (hyperemia, edema, erosions) around the appendiceal orifice.

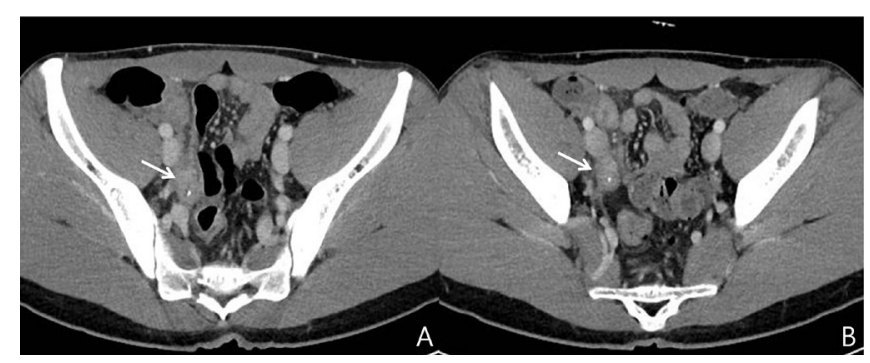

Fig.2: Contrast enhanced computed tomography (CT) of abdomen and pelvis. (A): CT scan before antibiotic therapy: edematous wall thickening of appendix with tiny appendicolith (arrow) (B): CT scan after four weeks of antibiotic therapy: No change was observed (arrow).
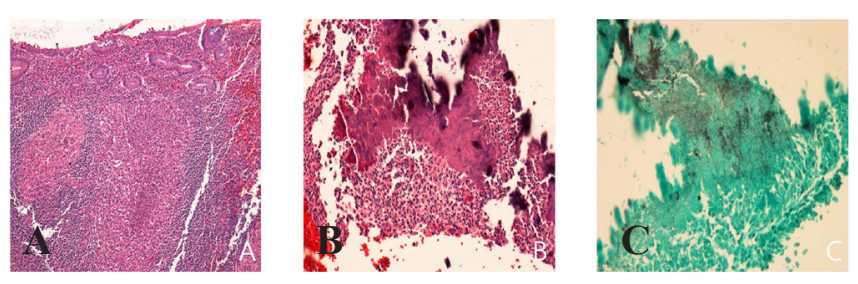

Fig.3: Histopathological findings. (A): The granulomas are predominantly located in the lamina propria, some of which are seen to develop central neutrophilic infiltration [hematoxylin \& Eosin (H\&E) stain, x100]. (B): A sulfur granule, an Actinomyces colony, surrounded by inflammatory cells (H\&E stain, x200). (C): Filamentous organisms are stained black on Grocott's methenamine silver stain (x400).

cecal region are common sites of involvement[9] and $65 \%$ of AA cases are associated with acute appendicitis [3]. 
The diagnosis of AA is difficult before surgery because it is a slowly progressive disease manifesting with non-specific signs and symptoms, laboratory, and radiological findings $[9,10]$. Therefore, in most cases diagnosis is possible only after the time of surgery, during which histologically, the specimen typically is characterized by a sulfur granule surrounded by inflamed tissue [8]. Once a diagnosis of AA is made, long-term antibiotic therapy is required to eradicate Actinomycetaceae bacteria and prevent local recurrence. Although there are no specific guidelines, penicillin is known to be effective in AA. If penicillin cannot be used, tetracycline, erythromycin, doxycyline, and clindamycin are other options [1]. The duration of antibiotic therapy depends upon the patient's baseline intraabdominal status.

Only a few cases of appendicitis arising from actinomycosis have been reported [2-7]. However, performing an interval appendectomy and tracking with $\mathrm{CT}$ examination during the period of non-operative management is where our case differs from previously reported ones. All patients except one among the previously reported cases underwent urgent surgery because of symptoms or radiologic findings of acute appendicitis and peri-appendiceal abscess. One patient among the previously reported cases [2] underwent interval appendectomy after CT-guided peri-appendiceal drainage and was not followed with $\mathrm{CT}$ before surgery.

Our case demonstrated that actinomycosis should be considered in patients with appendicitis, and a follow-up CT may be necessary in the presence of non-specific clinical manifestations. Actinomycosis must be considered especially if there is no change noted on $\mathrm{CT}$ examination. It is unclear whether initiation of antibiotic therapy affects prognosis, but we demonstrated that if we had recognized the condition early, we could have decided upon early operation to confirm diagnosis. To conclude, we report the case of a patient with appendicitis due to actinomycosis, who underwent interval appendectomy after four weeks of antibiotic therapy.

\section{Conclusion}

Although rare, surgeons should consider actinomycosis, with a high index of suspicion, in the differential diagnoses during non-operative management of appendicitis.

Contributors: HSK: manuscript writing, literature search, patient management; JHL: manuscript editing, histopathology. HSK will act as guarantor. Both authors approved the final version of the manuscript.

Funding: None; Competing interests: None stated.

\section{References}

1. Russo TA. Agents of actinomycosis. In: Mandell GL, Bennett JE, Dolin R, editors. Principles and practice of infectious disease. New York: Churchill Livingstone, 2005:2924-34.

2. Ken L, David J, Ken L, James K, Meng CN. Abdominal actinomycosis presenting as appendicitis: two case reports and review. JSCR. 2016;5:1-3.

3. Liu V, Val S, Kang K, Volcek F. Case report: actinomycosis of the appendix-an unusual case of acute appendicitis in children. J Pediatr Surg. 2010;45:2050-2052.

4. Kwak JH, Won EJ, Choi EH, Jung SE, Kim HY. Periappendiceal actinomycosis presenting as acute appendicitis. J Korean Assoc Pediatr Surg. 2015;21:710.

5. Lim SK, Choi HJ, Son HM, Choi YI, Cho MS. Actinomycosis presented as acute appendicitis. Ewha Med J. 2014;37:S15-18. [In Korean, English abstract].

6. Jee SB, Jang KS, Kim SH, Kim CJ. Actinomycosis of the appendix: A case report. J Korean Soc Coloproctol 2010;26:233-237. [In Korean, English abstract].

7. Erdal K, Hale T, Emin T, Halil K, Erkan Y, Gokhan M. Abdominal actinomycosis mimicking acute appendicitis. Can J Surg. 2008;51:109-110.

8. Huang CJ, Huang TJ, Hsieh JS. Pseudo-colonic carcinoma caused by abdominal actinomycosis: report of two cases. Int J Colorectal Dis. 2004;19:283-286.

9. Wong V, Turmezei T, Weston V. Actinomycosis. BMJ. 2011;343:d6099.

10. Lee IJ, Ha HK, Park CM, Kim JK, Kim JH, Kim $\mathrm{TK}$, et al. Abdominopelvic actinomycosis involving the gastrointestinal tract: CT features. Radiology. 2001;220:77-80. 